\title{
SURDOS E TERAPIA OCUPACIONAL: O QUE DIZEM AS PESQUISAS?
}

\author{
Jelson Budal Schmidt, Josyane Kamilla Theylacker e Priscila Murtinho Deud
}

\begin{abstract}
ACE
jelsonbudal@hotmail.com

Acesso DOI: http://dx.doi.org/10.34059/ciejop.2019v28i1-13

Introdução: A Terapia Ocupacional tem por competência a reabilitação e manutenção das atividades de vida diária aos que dela necessitam, tendo por preceitos $\mathrm{o}$ atendimento a todos os que precisarem de seus recursos para atendimento. Diante desta prerrogativa entende-se que as pessoas devem ser atendidas sem distinção alguma. Neste sentido, é importante conhecer o que dizem as pesquisas abordando a Terapia Ocupacional e a pessoa surda. Desse modo o presente artigo tem por objetivo conhecer o tema e apresentar o que as pesquisas com esta temática revelam. Metodologia: A pesquisa foi delimitada pelas revistas científicas virtuais Ufscar, USP, Revisbrato e pela base de dados Scielo, tendo a revisão bibliográfica como base. Resultados: Identificou-se que são poucos os artigos que abordam a pessoa com surdez e sua relação com Terapia Ocupacional no meio acadêmico e em alguns casos quando encontramos em artigos estes termos, é tido Libras como medida de peso ou o surdo como critério de exclusão das pesquisas. Mesmo com legislação vigente acerca de Libras e do atendimento à pessoas surdas assegurado é perceptível que há um desconhecimento destas sujeitos por parte de grande parcela dos ouvintes. Conclusão: Entende-se que o obstáculo a ser superado é em relação ao preconceito e também a comunicação. Os ouvintes, por temerem estabelecer comunicação por não saberem Libras acabam evitando atender o paciente surdo, que precisa desta atenção da mesma maneira que o ouvinte. É necessária, também, a popularização de Libras para que as pessoas eliminem o receio de atender os surdos e entendam que a única diferença neste atendimento é em relação à comunicação.
\end{abstract}

